\title{
Toward Universal Unified Cesarean Section Method in Africa
}

Stark $\mathrm{M}^{1 *}$, Mynbaev $\mathrm{O}^{1}$, Belci $\mathrm{D}^{1}$, Danilov $\mathrm{A}^{2,3}$, Vassilevski $\mathrm{Y}^{2,3}$, Ogutu $\mathrm{O}^{1,4}$

${ }^{1}$ The New European Surgical Academy, Berlin, Germany

${ }^{2}$ The Institute of Numerical Mathematics at the Russian Academy of Sciences

${ }^{3}$ The Sechenov University, Moscow, Russia

${ }^{4}$ School of Medicine University of Nairobi, Kenya

\section{Article History \\ Received: 19.09.2020 \\ Accepted: 09.10.2020 \\ Published: 17.10 .2020}

Journal homepage:

https://www.easpublisher.com/easjms

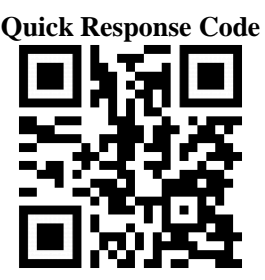

Abstract: The way to perform Cesarean Section (CS) Is different not just among countries and hospitals but even between obstetricians working in the same department. The postoperative outcome depends on the way how, and which surgical steps are performed. Therefore, it is important to use a universal and evidence-based method which has been compared in scores of studies with other methods and proved to show benefits, and is worldwide accepted. This method is the Misgav Ladach (Stark) operation, which has been developed while examining each single step for its necessity, and when so, for the most optimal way to perform it. The aim of this article is to share the method with our African colleagues, to explain the different steps and the logic behind them, in order to accept it for universal use all over the African continent.

Keywords: Cesarean Section, Misgav Ladach, Stark Cesarean.

Copyright (C) 2020 The Author(s): This is an open-access article distributed under the terms of the Creative Commons Attribution 4.0 International License (CC BY-NC 4.0) which permits unrestricted use, distribution, and reproduction in any medium for non-commercial use provided the original author and source are credited.

\section{INTRODUCTION}

During the last years we were honored to conduct surgical workshops and lectures in different West and East African countries. We were highly impressed with the knowledge and technical skills of our African colleagues, but observed that the CS technique used varied not only from hospital to hospital but also among obstetricians working in the same department, probably due to prevailing traditions and ways of learning. The same observation you can find worldwide in other countries, including American, Russian and European hospitals.

Aim of CS is to deliver baby according to indications with less harmful way for both, mother and newborn. Therefore, it is of utmost importance to use an optimal, evidence-based operation which was compared to other operative methods and proved to show the most favorable outcomes.

This Stark technique of CS was developed in Jerusalem at the Misgav Ladach Hospital during a process of three years, where different steps and their outcome were evaluated, such as the optimal way to perform laparotomy [1], suturing the uterus in one or two layers, and the necessity of suturing the peritoneum [2]. After extensive experience in hundreds of operations it was introduced during the $14^{\text {th }}$ FIGO congress which took place 1994 in Montreal [3].

Thereafter, surgeons from all over the world started to visit the Misgav Ladach hospital in Jerusalem. Among them were surgeons from the University of Uppsala, Sweden, and they adopted the technique, described its different steps [4] and conducted the first Scandinavian comparative study comparing this method to the traditional Pfannenstiel-Kerr operation [5]. The Mother and Child Unit at the university of Uppsala produced leaflets and a video film which were circulated in over 100 countries, including African ones.

Today there are scores of comparative studies from different countries in different continents. Without exception all shows advantages of this method, even if different parameters are evaluated. For example, less postoperative adhesion [6], less blood loss [7] and diminished need for analgesics compared to other methods [8], and significantly shorter duration [9].

At the university hospital of Kathmandu, the operation has been compared to the traditional one and proved also to be associated with shorter operative time with shorter incision to delivery time, quicker recovery, 
and lesser need for postoperative analgesics next to its cost-effectiveness [10].

In a study comparing the late outcome of the described method to the traditional one, five and more years after the operation, better long-term postoperative results in the women who were operated with this method were shown, less neuropathic and chronic pain and satisfaction about the appearance of the scar [11]. It seems needless to say that Cesarean Sections should be done just for justified indications in order to prevent the unavoidable late adverse effects on the uterus [12].

It will be difficult to compare the outcome among surgeons and hospitals if each surgeon is using a different method [13]. Therefore, it is suggested that this method should become the standardized universal method in Africa, also in order to enable comparison among different surgeons and hospitals.

\section{THE METHOD}

The patient is preferably operated under epidural or spinal anesthesia and placed in Trendelenburg position on the operation table with closed legs in order to avoid tension on the fascia during suturing.

Right-handed surgeon stands on the right side of the patient. The right hand is more sensitive and therefore the extension of the uterine opening will be limited. Also, when suturing the uterus, the tip of the needle goes away from the bladder with less risk of puncturing the bladder.

The laparotomy is performed with a modification of a method which was described for abdominal hysterectomy by the South African professor Sidney Joel Joel-Cohen in 1972 [14]. The first incision is done within the transverse skin lines which become visible when the skin is pulled toward the left iliac spine. The incision is very superficial cutting only through the cutis in a straight line about $3 \mathrm{~cm}$ below the line connecting both Spinae Iliacae Anteriores Superiores.

The deepening of the incision is done only in the central part of the incision, in the midline, where no significant blood vessels are running, and therefore hemostasis is needed very rarely. When the fascia is reached, a transverse incision ef about $4-5 \mathrm{~mm}$ is done. Straight scissors with round tips are used to open the fascia. One blade is placed above the fascia in the hole that was created with the scalpel and the other one below the fascia. The tips of the scissors should open about $4 \mathrm{~mm}$ in order to not to damage blood vessels, which will move away from the round tips. The scissors are pushed first to the left and then to the right to open the fascia, as far as needed. The opening of the fascia is done below the subcutaneous tissue.
The surgeon inserts two index fingers between the straight muscles and pulls the fascia up and down and then both, the surgeon and the assistant are pulling the muscles laterally with their index and middle fingers, including fat tissue and blood vessels, as much as needed. The blood vessels have lateral sway and will move laterally without tearing or causing bleeding. The traction should be done slowly to enable the tissues to adjust to the stretching.

In order to avoid damaging any intraabdominal structures the peritoneum should be opened by repeated bi-digital stretching above the bladder until a small opening appears [15], and thereafter enlarging the opening by stretching the opening. Hand speculum is inserted thereafter to the lower part of the opening.

Although the uterus and the cervix comprise one organ and develop together, but from different sources, their structure and function during delivery are completely different [12]. In the upper part of the uterus, a higher percentage of muscle tissue exists which is getting poor in the cervical part [16]. The uterus should be opened where there is little muscle tissue as possible, in the lowest segment of the uterus which is composed partly by the lower part of uterus and the upper part of cervix [12]. Therefore, the plica and the bladder should be pushed down in order to expose the lower segment of the uterus. The plica is opened above the bladder and pushed down with the index finger of the right hand.

Thereafter the middle part of the lower segment of the uterus is incised transversely and superficially for about $4 \mathrm{~cm}$. The uterine wall should not be opened completely with the scalpel to avoid cutting of the presenting part of the baby. It should be penetrated with the index finger. Thereafter, the right thumb extends the opening of uterus to the left while the left index finger pulls to the right side.

If the amniotic sack was not ruptured, it should be perforated either with a tip of the finger or scalpel. The hand speculum is removed, and the surgeon inserts the right hand into the uterus encircling the presenting part and lifting it up, while the assistant is pushing the uterine fundus down. The umbilical cord is clamped and the baby is given to the midwife.

The optimal way is the detachment of the placenta spontaneously, but should spontaneous detachment not be the case, it should be removed manually, although this is associated with more bleeding [17]. After removal of the placenta the uterus is exteriorized while being contracted by two hands in order to reduce bleeding.

After re-inserting the speculum, the central part of the lower layer of the opened uterus is grasped with a forceps. The uterus should be sutured in one 
layer with a big needle, preferably of $80 \mathrm{~mm}$. The more suture material is used, the more foreign body is left behind for several weeks, therefore the use of one layer with a big needle will leave less suture material behind [18]. Second layer anyhow does not add any value [19]. The sutures should be locked to achieve immediate hemostasis. There is no risk for damage of the trapped tissues because the uterus starts involution immediately, the sutures loosen, and therefore the blood supply is not restricted. The less suture material is used, less foreign body reaction to the suture material, with less pain and irritation to the bladder. If necessary, extra single sutures are done to secure hemostasis. The sutures keep the wound edges together for several hours, then with further contraction and involution of the uterus excess sutures harmfully impacts on wound healing and initiates postsurgical adhesion formation and other complications of CS scar with development of the uterine morbidity syndrome [12].

Abdominal towels for packing the abdomen to push away the gut should be avoided as they might cause adhesions [20]. After suturing the uterus blood clots should be removed by hand from behind the uterus in the Douglas pouch or in front of the bladder, but not liquid blood because it will be absorbed from the intraperitoneal cavity within hours. The exteriorized uterus is placed back into the abdominal cavity.

The peritoneum should be left open, as a new one develops after short time, and when sutured more adhesions occurs $[21,22]$. Only the fascia and the skin should be sutured.

As the fascia was opened above the plica arcuate, on the lateral sides two layers of it can be seen, and they should be included while suturing in order to avoid herniation. The surgeon places two straight artery forceps on both ends of the incision, holding both layers together. Two additional artery forceps are placed on the upper and lower aspects of the fascia at the third quarter of its length toward the assistant. The assistant holds and lifts them. The two instruments should be held by the assistant not too far from each other in order to prevent tension on the suture material, but not too close to each other in order to enable the surgeon to see the structures below while suturing. The surgeon continues to suture toward the assistant until the third quarter of the cut is reached. The assistant removes the upper and lower forceps and lifts the lateral forceps. The subcutaneous tissue should be observed for possible bleeding, which usually is not the case.

The skin is closed with as few sutures as possible, usually, by one midline Donati suture with a big needle, including also the subcutaneous tissue. This should be followed by two additional Donati stitches between the midline and the lateral end of the incision. The open spaces between the sutures, in case there are any, can be adapted by Allis clamps for couple of minutes, and more sutures should be placed if adaptation was not reached. The less stitches, the better the drainage. Few hours after the operation, the bandage should be replaced.

Early hydration is recommended [23, 24]. The mother should be encouraged to move as soon as possible and take care on her baby.

Only ten instruments are necessary: scalpel, straight scissors with round tips, Doyen/Fritsch retractor, uterine clamp, four straight clamps, surgical forceps, uterine forceps, and needle holder. Once in a while, two or three Allis clamps can be used for adaptation of the skin when necessary.

\section{Implementation of the method in Africa}

This operation has already been introduced in East and West Africa by the New European Surgical Academy and is already in use in several African countries, even if with some modifications under the name "Misgav Ladach" or the "Stark Cesaraen".

In a study done in Dar es salaam the operation resulted in short operation time and less suture material needed, reduced blood loss and rapid mobilization [25].

In a study at the Nazareth Hospital, Kiambu County, Kenya, the operation was compared to the traditional one. The average operation time proved to be significantly shorter (20, 4 Min vs. 30,4$)$ next to less wound infections and significantly less need for analgesics. Also, the developed post-operative hypertrophic scars were at the 6-week follow-up significantly less than in the traditional method. The authors concluded that this method should become standard in low income countries and particularly in rural hospitals [26].

In a study at the university hospital in Dakar, Senegal, it was shown that the skin incision to delivery and the whole procedure was shorter with less use of suturing material and operation costs, and therefore it was suggested as an alternative to the traditional method [27].

A study in Sub-Saharan African countries revealed that in Tanzania less blood loss, less suture material and shorter operation time was recorded with this operation. In Kenya this operation had lower risk of surgical site infection than in standard midline incision, with shorter operation time and less need for analgesia [28].

In Burkina Faso this method is used by $86.5 \%$ of the obstetricians and $95.3 \%$ of nurses performing CS [29]. 
The conclusion of a comparative study in Burkina Faso was that this CS is a reliable technique, fast and simple which eliminates unnecessary time of surgery and limits the risk of complications. It is an alternative in the practice of emergency Caesareans in under-medicalized and low-income countries, and dissemination at national level was recommended [30].

\section{The all African Surgical Database}

As standardization of the surgical method is of importance, and in order to compare the outcome of the operation among surgeons, hospitals and countries concerning the methods they use, the New European Surgical Academy with the assistance of Marchuk Institute of Numerical Mathematics of the Russian Academy of Sciences (INM RAS) in Moscow developed the All African Surgical Database project (for Cesarean Sections, Vaginal Hysterectomy and Endoscopy), where surgeons are reporting electronically their individual performed surgical steps, as well as the post-operative follow up. This enabled for the first time an exact evaluation of each operative detail and the influence of the operative method on its outcome (31).

\section{CONCLUSION}

The Misgav-Ladach (Stark method) of Caesarean Section has advantages over the traditional operation using the Pfannenstiel incision, suturing the uterus with two layers, closing peritoneum and suturing the skin intradermally. The incision to delivery and the duration of the operation is significantly shorter, with reduced amounts of bleeding and suture material, less febrile morbidity and lower costs. No negative effects of the new operation technique were ever reported. This operation is suggested as a standardized and universal use for all African countries. The New European Surgical Academy is willing to conduct surgical workshops all over the continent whenever wished or needed.

\section{REFERENCES}

1. Stark, M., \& Finkel, A. R. (1994). Comparison between the Joel-Cohen and Pfannenstiel incisions in cesarean section. European Journal of Obstetrics \& Gynecology and Reproductive Biology, 53(2), 121-122.

2. Stark, M. (1993). Clinical evidence that suturing the peritoneum after laparotomy is unnecessary for healing. World journal of surgery, 17(3), 419.

3. Stark, M. (1994). Technique of Caesarean section: the Misgav Ladach method in women's health today: perspectives on current research and clinical practice. Popkin DR, Peddle LJ, eds. In Proceedings of the XIV World Congress of Gynaecology and Obstetric. Montreal, Parthenon Publishing Group, New York Sept (Vol. 81).

4. Holmgren, G., Sjöholm, L., \& Stark, M. (1999). The Misgav Ladach method for cesarean section, method description. Acta obstetricia et gynecologica Scandinavica, 78(7), 615-621.

5. Darj, E., \& Nordstrøm, M. L. (1999). The Misgav Ladach method for cesarean section compared to the Pfannenstiel method. Acta obstetricia et gynecologica Scandinavica, 78(1), 37-41.

6. Nabhan, A. F. (2008). Long-term outcomes of two different surgical techniques for cesarean. International Journal of Gynecology \& Obstetrics, 100(1), 69-75.

7. Messalli, E. M., Cobellis, L., \& Pierno, G. (2001). Cesarean section according to Stark. Minerva Ginecologica, 53(5), 367-371.

8. Hudić, I., Bujold, E., Fatušić, Z., Skokić, F., Latifagić, A., Kapidžić, M., \& Fatušić, J. (2012). The Misgav-Ladach method of cesarean section: a step forward in operative technique in obstetrics. Archives of gynecology and obstetrics, 286(5), 1141-1146.

9. Belci, D., Kos, M., Zoricić, D., Kuharić, L., Slivar, A., Begić-Razem, E., \& GRDINIć, I. (2007). Comparative study of the"Misgav Ladach"and traditional Pfannenstiel surgical techniques for cesarean section. Minerva ginecologica, 59(3), 231.

10. Poonam, B. B., Singh, S. N., \& Raina, A. (2006). The Misgav Ladach method: a step forward in the operative technique of caesarean section. Kathmandu Univ Med J (KUMJ), 4(02), 198-202.

11. Belci, D., Di Renzo, G. C., Stark, M., Đurić, J., Zoričić, D., Belci, M., \& Peteh, L. L. (2015). Morbidity and chronic pain following different techniques of caesarean section: a comparative study. Journal of Obstetrics and Gynaecology, 35(5), 442-446.

12. Mynbaev, O., Babenko, T. I., Ahmadi, F., Raimondo, I., Kosmas, I. P., Mishutina, A. A., ... \& Javam, M. (2018). Uterine morbidity: Cesarean section scar complications. In Hysteroscopy (pp. 421-468). Springer, Cham.

13. Stark, M., Gerli, S., \& Di Renzo, G. C. (2009). The importance of analyzing and standardizing surgical methods. Journal of Minimally Invasive Gynecology, 16(2), 122-125.

14. Joel-Cohen, S. (1972). Abdominal and vaginal hysterectomy: new techniques based on time and motion studies. Heinemann Educational Books.

15. Stark, M. (2009). In the era of 'non-closure of the peritoneum', how to open it?(Not every simple method is optimal, but every optimal method is simple). Acta obstetricia et gynecologica Scandinavica, 88(1), 119-119.

16. Rorie, D. K., \& Newton, M. (1967). Histologic and chemical studies of the smooth muscle in the human cervix and uterus. American journal of obstetrics and gynecology, 99(4), 466-469.

17. Hidar, S., Jennane, T. M., Bouguizane, S., Lassoued, L., Bibi, M., \& Khaïri, H. (2004). The effect of placental removal method at cesarean delivery on perioperative hemorrhage: a 


$\begin{array}{llllll}\text { randomized clinical trial ISRCTN } & \text { International Journal of } & \text { Obstetrics \& } \\ \text { 49779257. European Journal of Obstetrics \& } & \text { Gynaecology, 107(2), 209-216. } & \end{array}$
Gynecology and Reproductive Biology, 117(2), 179-182.

18. Stark, M. (2016). Does size matter?. Journal of the Turkish German Gynecological Association, 17(3), 175.

19. Chapman, S. J., Owen, J., \& Hauth, J. C. (1997). One-versus two-layer closure of a low transverse cesarean: the next pregnancy. Obstetrics \& Gynecology, 89(1), 16-18.

20. Down, R. H. L., Whitehead, R., \& Watts, J. M. (1979). Do surgical packs cause peritoneal adhesions?. Australian and New Zealand Journal of Surgery, 49(3), 379-382.

21. Ellis, H. (1980). Internal overhealing: the problem of intraperitoneal adhesions. World journal of Surgery, 4(3), 303-306.

22. Malvasi, A., Tinelli, A., Guido, M., Zizza, A., Farine, D., \& Stark, M. (2010). Should the visceral peritoneum at the bladder flap closed at cesarean sections? A post-partum sonographic and clinical assessment. The Journal of Maternal-Fetal \& Neonatal Medicine, 23(7), 662-669.

23. Tan, P. C., Alzergany, M. M., Adlan, A. S., Noor Azmi, M. A., \& Omar, S. Z. (2017). Immediate compared with on-demand maternal full feeding after planned caesarean delivery: a randomised trial. BJOG: An International Journal of Obstetrics \& Gynaecology, 124(1), 123-131.

24. Guedj, P., Eldor, J., \& Stark, M. (1991). Immediate postoperative oral hydration after caesarean section. Asia-Oceania Journal of Obstetrics and Gynaecology, 17(2), 125-129.

25. Björklund, K., Kimaro, M., Urassa, E., \& Lindmark, G. (2000). Introduction of the Misgav Ladach caesarean section at an African tertiary centre: a randomised controlled trial. BJOG: An 